\title{
Correction to: An Archaeology of Nineteenth-Century Consumer Behavior in Melbourne, Australia, and Buenos Aires, Argentina
}

\author{
Correction to: \\ P. Ricardi, An Archaeology of Nineteenth-Century Consumer \\ Behavior in Melbourne, Australia, and Buenos Aires, Argentina, \\ Contributions To Global Historical Archaeology, \\ https://doi.org/10.1007/978-3-030-21595-8
}

The book has been inadvertently published with an incorrect reference year for Lea $\&$ Perrins Worcestershire club sauce stopper in three instances. The correct year in all the three instances is 1958 .

- On page 109 - Chapter 5 - the sentence beginning "A Lea \& Perrins Worcestershire sauce stopper dating from 1840 to $1858 \ldots$... should say 1840 to 1958.

- On page 130 - 1857 - Chapter 6 - should be changed 1958.

- Appendix 1 - Again, the Lea \& Perrins date should say 1840 to 1958.

The updated online versions of these chapters can be found at https://doi.org/10.1007/978-3-030-21595-8_5 https://doi.org/10.1007/978-3-030-21595-8_6 https://doi.org/10.1007/978-3-030-21595-8 